\title{
Análise citológica do líquido peritoneal
}

\section{Cytological analysis of peritoneal fluid}

\section{Samuel Ricardo Comar ${ }^{[a]}$, Tamirys Schulz ${ }^{[b]}$, Nicolle de Araújo Machado ${ }^{[c]}$, Franciane da Silva} França $^{[\mathrm{d}]}$, Patrícia Haas ${ }^{[\mathrm{e}]}$

\section{Resumo}

0 líquido peritoneal ou ascítico se apresenta como uma ultrafiltração do plasma contido na cavidade peritoneal. Sua principal função é a proteção da cavidade abdominal, banhando-a e lubrificando-a, reduzindo, assim, 0 atrito entre os órgãos 0 que permite melhor mobilidade destes. Alterações na sua condição fisiológica podem se dar por vários fatores, como variações nas forças hidrostáticas no sistema circulatório e pressão oncótica do plasma. Essas alterações podem levar a um acúmulo de líquido na cavidade abdominal, ocasionando a ascite. Doenças crônicas do fígado, como a cirrose, associadas à hipertensão portal são as causas mais frequentes de ascite. A análise laboratorial fornece dados essenciais que auxiliam 0 clínico no diagnóstico e conduta terapêutica eficaz. É constituída da avaliação das características físicas (volume, coloração e aspecto), testes bioquímicos, contagem celular e análise diferencial das células nucleadas. A metodologia adotada, assim como as características do fluido ascítico devem ser muito bem dominadas pelos profissionais envolvidos, o que garante uma melhor qualidade dos resultados.

Palavras-chave: Ascítico. Líquido peritoneal. Análise laboratorial. Citologia.

\begin{abstract}
The peritoneal ou ascitic fluid is presented as an ultrafiltered of plasma in the peritoneal cavity. Its main function is protecting the abdominal cavity by lubricating it, thus reducing the friction between the bodies, which allows for their greater mobility. Changes in its physiological condition can occur by several factors such as changes in hydrostatic forces in the circulatory system and plasma oncotic pressure. These changes may lead to an accumulation of fluid in the abdominal cavity, causing ascites. Chronic liver diseases such as cirrhosis, associated with portal hypertension are the most fronts of ascites. Laboratory analysis provides essential data that assist the clinician in diagnosis and effective therapy. It consists of evaluation of physical characteristics (volume, color and appearance), biochemical tests, cell counts and differential analysis of nucleated cells. The method used and the characteristics of the ascitic fluid should be performed by thoroughly familiarized professionals, which ensures better quality of results.
\end{abstract}

Keywords: Ascitic fluid. Peritoneal fluid. Laboratorial analisys. Cytology. [a] Mestre em Ciências Farmacêuticas (Área de concentração: Análises Clínicas) pela Universidade Federal do Paraná (UFPR), farmacêutico bioquímico da seção de Hematologia da Unidade de Apoio Diagnóstico do Hospital de Clínicas da Universidade Federal do Paraná (UFPR), Curitiba, PR - Brasil.

${ }^{[b]}$ Especialização em Citologia Cérvico Vaginal e Líquidos Corporais, Universidade Federal de Santa Catarina (UFSC), Florianópolis, SC - Brasil.

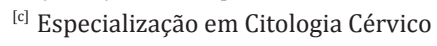
Vaginal e Líquidos Corporais Universidade Federal de Santa Catarina (UFSC), Florianópolis, SC - Brasil, e-mail: ni_machado@hotmail.com

${ }^{\text {[d] }}$ Mestranda do Programa de Pós-Graduação em farmácia da Universidade Federal de Santa Catarina (UFSC), Florianópolis, SC - Brasil.

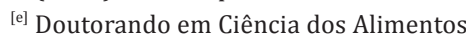
pela Universidade Federal de Santa Catarina (UFSC), professor adjunto I da Universidade Federal de Santa Catarina (UFSC), Florianópolis, SC Brasil, e-mail: patricia.haas@ufsc.br

Recebido: 24/02/2010

Received: 02/24/2010

Aprovado: 14/10/2010

Approved: 10/14/2010 


\section{Argumentações}

0 peritônio é uma membrana serosa, lisa e delicada, constituída de fibroblastos, matriz extracelular, vasos sanguíneos e células mesoteliais, que reveste a parede e vísceras do abdômen e pélvis (1). Apresenta dois folhetos, que são o parietal, que reveste a cavidade abdominal e o visceral que reveste os órgãos (2-4). Entre esses folhetos, existe uma cavidade virtual denominada cavidade peritoneal, por onde circula o líquido peritoneal ou ascítico (5). A cavidade peritoneal contém, em condições normais, aproximadamente $50 \mathrm{~mL}$ de fluido, o qual se apresenta sob a forma de um líquido transparente, amarelo claro, estéril e viscoso e é produzido pelas células da membrana como um ultrafiltrado do plasma (6). Tanto a sua produção quanto sua reabsorção é dependente de vários fatores, como a permeabilidade dos capilares peritoneais, as forças hidrostáticas no sistema circulatório, a pressão oncótica do plasma e a reabsorção linfática (7-9).

A principal função do líquido ascítico é a proteção da cavidade abdominal, banhando-a e lubrificando-a, reduzindo, assim, o atrito entre os órgãos e permitindo sua movimentação durante o processo da digestão (4). Foram descobertos, também, importantes papéis no transporte de fluidos e células, no processo inflamatório, no reparo tecidual, na lise de depósitos de fibrina, na proteção contra microrganismos invasores e possivelmente na disseminação tumoral $(5,10)$.

Evidências sugerem que um distúrbio de transporte de eletrólitos e fluidos na monocamada de células mesoteliais atuam como um importante fator na formação de derrames, no qual há acúmulo de líquido na cavidade abdominal, seja por aumento da produção e/ou deficiência de remoção $(7,11-13)$. 0 acúmulo de fluido dentro da cavidade peritoneal constitui uma efusão peritoneal, a qual assinala que o paciente possui ascite. Esta, por sua vez, pode ser classificada de acordo com o grau de severidade e resposta terapêutica, em ascite descomplicada, complicada e ascite refratária (14). A fim de se obter a confirmação etiológica da ascite, realiza-se um procedimento cirúrgico chamado paracentese, que consiste na remoção de líquido ascítico da cavidade peritoneal. Com a diferenciação do fluido ascítico em transudato ou exsudato, a determinação da diferença entre a concentração de albumina no soro e no líquido ascítico é de fundamental importância para o fornecimento de subsídios para uma posterior abordagem clínica e laboratorial $(2,13)$.

Tendo em vista a correlação que se observa entre a presença de hipertensão portal e o gradiente entre a albumina do soro e a albumina do líquido ascítico, pode-se afirmar que níveis maiores ou iguais a $1 \mathrm{~g} / \mathrm{dL}$ associados a graus de proteínas inferiores a 3,0 g/dL sugerem o diagnóstico de cirrose. Naqueles casos em que a relação for menor ou igual a $1,1 \mathrm{~g} / \mathrm{dL}$, acompanhado da presença de níveis proteicos elevados, deveria se pensar em doença peritoneal e, quando ambos os parâmetros estivessem acima dos níveis críticos propostos, a hipótese seria de hipertensão portal pós-sinusoidal $(2,6,15)$.

Doenças crônicas do fígado, como a cirrose, associadas à hipertensão portal são as causas mais frequentes de ascite $(9,12,16,17)$. Outras etiologias menos comuns, porém não menos importantes, incluem neoplasia maligna principalmente de ovário e mama, insuficiência cardíaca, nefropatia, tuberculose, doenças pancreáticas e peritonite bacteriana espontânea $(13,16)$. Pacientes com grande derramamento de líquido ascítico podem desenvolver hérnias inguinais, umbilicais e incisionais $(2,18)$.

0 diagnóstico precoce da ascite é extremamente importante, considerando que algumas formas são benignas e possuem bons prognósticos. No entanto, outras podem se expressar como forma de patologias muito agressivas, potencialmente letais, que, se não descobertas a tempo, podem apresentar poucas chances de cura (7). Nos casos em que há suspeita de traumatismo fechado na cavidade abdominal, de lesão interna associada a sinais clínicos não característicos e peritonite aguda ou pancreatite, realiza-se a lavagem peritoneal por meio da inserção de 1 litro de solução salina ou de Ringer para posterior análise laboratorial. 0 líquido é obtido por drenagem gravitacional, sendo que, para um resultado confiável, pelo menos $600 \mathrm{~mL}$ devem ser recuperados. As amostras geralmente são enviadas ao laboratório somente para o exame citológico (8).

\section{Análise laboratorial do líquido ascítico}

1. Coleta da amostra: pacientes com sintomas e suspeita de ascite têm seu diagnóstico confirmado pela ultrassonografia, que detecta volumes variados de fluido. Ela auxilia tanto no diagnóstico quanto na escolha do melhor local para a realização da paracentese, 
especialmente quando se lida com um volume pequeno de líquido ascítico (8). Em geral, esse procedimento é seguro, mas os riscos iatrogênicos não são isentos. As principais complicações são relacionadas à perfuração de órgãos abdominais, desvio da agulha do local indicado, deposição de fragmentos do catéter no local da incisão e eventuais sangramentos (13). A técnica é contraindicada nos casos de paciente inconsciente não colaborativo com o procedimento, infecções na pele, gravidez e distensão intestinal (19). Uma paracentese bem sucedida deve satisfazer aos seguintes critérios: quantidade suficiente de fluido na primeira coleta, ausência de complicações e o mínimo de desconforto ao paciente durante o procedimento (20).

0 paciente é colocado em uma posição supina, com uma inclinação de $30^{\circ}$ a $45^{\circ}$ para a retirada de grandes volumes ou em decúbito lateral para a retirada de pequenos volumes. Os locais indicados para incisão da agulha a fim de evitar a perfuração de redes vascularizadas estão localizados na linha média, $2 \mathrm{~cm}$ abaixo do umbigo ou numa área considerada incômoda no quadrante inferior esquerdo, lateralmente ao músculo retoabdominal. A agulha é inserida na parede abdominal, após anestesia local. A agulha utilizada possui calibre 22 e é anexada a uma seringa que pode variar de 20 a $50 \mathrm{~mL}$. A pele é puxada de $1 \mathrm{a} 2 \mathrm{~cm}$ da sua posição natural para evitar o retorno de líquido na hora da perfuração. Então, a agulha é inserida suavemente, e a aspiração feita de forma lenta permitindo o livre retorno do fluido ascítico. Após coletar a quantidade suficiente de amostra, a agulha é retirada rapidamente, e, assim, a pele retorna à sua posição normal. Um curativo é feito no local, e a amostra é encaminhada para as devidas análises laboratoriais $(20,21)$.

É necessário um mínimo de $30 \mathrm{~mL}$ para a avaliação completa do líquido ascítico. Se possível, pelo menos $100 \mathrm{~mL}$ devem ser fornecidos para o exame citológico. As amostras devem ser coletadas em três tubos identificados com nome, número de registro do paciente e data da coleta. 0 primeiro deve conter EDTA ou heparina ( 1 a 2 gotas para $5 \mathrm{~mL}$ ) para a contagem global e diferencial. 0 segundo, sem anticoagulante, é utilizado para as análises bioquímicas, e o terceiro se destina à microbiologia e deve ser estéril $(6,7,22)$.

2. Transporte e Armazenamento: a amostra deve ser analisada o mais rápido possível, no entanto, caso o exame citológico não possa ser realizado imediatamente após a coleta, a amostra deve ser refrigerada entre $2^{\circ}$ e $8^{\circ} \mathrm{C}$ para que suas características morfológicas sejam mantidas por até $48 \mathrm{~h}(22)$.
3. Preparo da amostra: para a contagem de células nucleadas em câmara, utilizam-se amostras frescas, homogeneizadas e não centrifugadas. No entanto, na confecção da lâmina, deve-se lançar mão de uma ressuspensão do sedimento obtido por centrifugação em baixa rotação em solução salina. A sobreposição celular deve ser mínima. Em concentrações celulares ideais, uma monocamada de células é formada, o que facilita a sua visualização. Para isto, deve-se primeiramente avaliar a quantidade celular de cada amostra, e se for o caso, realizar a sua diluição pela adição de solução salina, $\mathrm{NaCl}$ 0,9\%. Amostras coaguladas, sem identificação e envelhecidas são rejeitadas (22).

4. Exame físico: a primeira análise após a coleta é o exame macroscópico. 0 aspecto visual do derrame (citrino, hemorrágico, purulento, etc.) é o critério inicial para agrupar diversas hipóteses diagnósticas e direcionar para exames específicos de análise laboratorial, além de permitir adotar medidas terapêuticas imediatas, como a drenagem no caso de empiema. 0 aspecto e a coloração devem ser anotados antes e após a centrifugação $(6,7)$.

Fisiologicamente, o líquido peritoneal ou ascítico é transparente, amarelo claro, estéril e viscoso, mas, em alguns casos, ele pode sofrer transformações como, por exemplo, apresentar turbidez em virtude das infecções bacterianas, coloração esverdeada em perfurações do trato gastrointestinal, pancreatite e colecistite, um aspecto leitoso que não clareia após a centrifugação em efusão quilosa ou pseudoquilosa $(6,8)$. Um líquido macroscopicamente hemorrágico deve ser diferenciado de punção traumática, evitando, assim, erros de diagnóstico. Na punção traumática, o clareamento do fluido ascítico é observado no decorrer da paracentese e na ascite hemorrágica, pequenas quantidades de sangue colorem aproximadamente um litro de líquido peritoneal de vermelho vivo e opaco, de modo que as impressões não podem ser lidas a partir do tubo de lavagem. Isso corresponde a uma contagem eritrocitária de $100.000 / \mu \mathrm{L}(7,8)$.

5. Contagem global de células: a contagem global de células é uma etapa muito importante para fazer a diferenciação da amostra entre transudato e exsudato. Os tipos celulares que podem ser encontrados no líquido peritoneal são os eritrócitos e as células nucleadas, que incluem leucócitos e células mesoteliais. A contagem global dessas células é realizada comumente em câmara de Neubauer. No entanto pode ser realizada em qualquer retículo de contagem (8). 
As células nucleadas são contadas nos quatro quadrantes externos da câmara de Neubauer, cujo volume total é de $0,4 \mathrm{~mm}^{3}$. Algumas amostras podem ser contadas sem a realização de uma diluição, e neste caso, o fator de conversão para microlitros é 2,5. Já em amostras com elevada celularidade, pode-se realizar uma diluição em solução aquosa de fucsina $0,2 \%$ na proporção (1:20). Essa solução otimiza a contagem, sobretudo por corar o núcleo das células nucleadas e por provocar lise dos eritrócitos, os quais, dependendo da quantidade, dificultam a contagem. Neste caso, o fator de conversão da câmara é multiplicado pela diluição, passando a ser igual a $50(1,8)$.

Para obtenção de uma contagem mais precisa e confiável, esta deve ser realizada em ambos os lados do hemocitômetro. Se os valores obtidos resultarem em uma diferença maior que $10 \%$ entre si, o procedimento deve ser realizado novamente, pois esse fato indica erros técnicos de preenchimento e montagem da câmara (22).

A contagem de eritrócitos pode ser igualmente realizada em câmara de Neubauer, porém a área de contagem é a parte central. 0 procedimento de contagem de eritrócitos varia de acordo com a celularidade da amostra (Tabela 1) (22).

Tabela 1- Procedimento de contagem global de eritrócitos em câmara de Neubauer, conforme a celularidade presente na amostra

\begin{tabular}{cc}
\hline Celularidade & Procedimento de contagem \\
\hline BAIXA & Contar os 25 quadrados \\
maiores e multiplicar por 10. \\
INTERMEDIÁRIA & $\begin{array}{c}\text { Contar } 5 \text { quadrados maiores e } \\
\text { multiplicar por } 50 .\end{array}$ \\
ALTA & Contar 1 quadrado maior e \\
& multiplicar por 250. \\
ALTíSSIMA & Fazer diluição com salina e \\
(sobreposição de eritrócitos) & multiplicar o resultado final \\
& pelo fator da diluição. \\
\hline
\end{tabular}

Fonte: Dados da pesquisa.

6. Contagem diferencial de leucócitos: o papel da contagem leucocitária do líquido ascítico, e sua análise diferencial, é de extrema importância na sugestão diagnóstica e consequente conduta terapêutica adotada pelo clínico.

Diferentes procedimentos e equipamentos podem ser utilizados para a confecção da lâmina onde se realiza a contagem diferencial, como a câmara de Suta, a citocentrifugação e a centrifugação em tubo. A câmara de Suta possui um sistema de filtros de papel, que absorvem a parte líquida do ascítico, concentrando, assim, as células, o que fornece um esfregaço de boa qualidade. A lâmina é introduzida na câmara e coberta com um papel absorvente, o qual deve conter um halo de diâmetro discretamente menor que o diâmetro do tubo conector da câmara. 0 tubo conector é torcido até tocar na lâmina, e então um aperto deve ser dado de modo a permitir a absorção da amostra por capilaridade. Na continuação do processo, o líquido é colocado na câmara, sendo que a quantidade necessária é dependente da quantidade de leucócitos presentes na amostra. Depois de a lâmina seca, o tubo conector e o papel absorvente são retirados de cima da lâmina, tomando o devido cuidado para que as células aderidas não sejam arrastadas. Então, a coloração da lâmina é feita com May Grunwald-Giemsa ou outros corantes de Romanowsky (22).

Na preparação da lâmina por citocentrifugação, a amostra é centrifugada em baixa rotação (1000 rpm), e o sedimento obtido é ressuspenso em solução salina. No citofunil é adicionado $100 \mu \mathrm{l}$ da amostra, a qual é processada de acordo com o protocolo de funcionamento desse aparelho. As células ficam concentradas, visto que o líquido sobrenadante é absorvido pelo papel filtro. Após a secagem da lâmina, realiza-se a coloração (22).

Após a lâmina pronta, realiza-se a contagem diferencial celular. Primeiramente observa-se a distribuição e agrupamento celular, em objetiva de 10x e 40x e então se muda para a objetiva de imersão (100x) em que a diferenciação celular é propriamente feita. As células podem sofrer alterações após a citocentrifugação mostrando-se distorcidas com vacúolos e projeções citoplasmáticas, fendas nucleares, nucléolos proeminentes e agrupamentos celulares semelhantes à neoplasia (22).

As contagens celulares variam de acordo com a formação e resolução da ascite, como a diurese que pode aumentar a contagem leucocitária de 300 células/ $\mu$ l até 1.000 células/ $\mu \mathrm{l}(8)$.

7. Considerações sobre a análise morfológica das células: primeiramente, uma visão geral da qualidade de uma amostra citológica é realizada com o auxílio das objetivas de 10x e 40x. Nessas ampliações, o examinador pode estimar a celularidade da amostra, examinar agregados celulares, identificar agentes infecciosos grandes como, por exemplo, leveduras 
e elementos fungoides e determinar as melhores localizações da lâmina, onde as células estão distribuídas em uma monocamada, para se observar posteriormente em maiores aumentos. A observação em aumento de 1.000x é utilizada para examinar as bactérias, a estrutura das células e outras estruturas pequenas tais como inclusões celulares. 0 citodiagnóstico enfatiza a aparência geral das células e seus núcleos. As características celulares importantes incluem a celularidade da amostra, a distribuição celular, tamanho e forma das células e a aparência citoplasmática. As características nucleares mais importantes incluem o tamanho, a forma e a posição do núcleo dentro da célula, o número de núcleos atuais; o padrão da cromatina do núcleo; a aparência do nucléolos e a presença de figuras de mitose. O tamanho do núcleo das células é avaliado frequentemente com relação à quantidade de citoplasma. A relação núcleo citoplasma $(\mathrm{N}: \mathrm{C})$ é uma indicação da proporção entre o tamanho do núcleo e o volume citoplasmático. As células epiteliais maduras, bem diferenciadas, tendem a ter núcleos pequenos e uma baixa relação $\mathrm{N}: \mathrm{C}$, enquanto as células epiteliais malignas, indiferenciadas, têm frequentemente grandes núcleos e uma relação $\mathrm{N}: \mathrm{C}$ elevada. A forma do núcleo varia de acordo com o tipo celular. A maioria das células normais tem um único núcleo; entretanto algumas células normais podem conter múltiplos núcleos. Por exemplo, algumas células mesoteliais são binucleadas, e alguns macrófagos podem ser multinucleados. Os padrões apresentados pela cromatina nuclear geralmente incluem cromatina de distribuição uniforme e finamente granulada, cromatina de distribuição irregular e finamente granulada, cromatina grosseira e granular com distribuição uniforme e cromatina grosseira e granular com distribuição irregular. A cromatina finamente granulada indica geralmente a imaturidade nuclear. Alguns núcleos como, por exemplo, núcleos de linfócitos maduros, contêm frequentemente alguns agrupamentos de cromatina que simulam nucléolos proemientes. As figuras de mitose indicam divisão celular ativa e pode ser uma característica celular normal em alguns tecidos, tais como a medula óssea e o fígado, quando forem encontradas em baixas quantidades. Números elevados de figuras de mitose indicam anomalias, tais como a neoplasia. Os nucléolos aparecem como espaços desobstruídos, circulares dentro do núcleo das células coradas por corantes de Romanoswski. Muitas células normais contêm frequentemente um ou vários nucléolos pequenos. Os nucléolos grandes e irregulares são considerados anormais. Núcleos com numerosos nucléolos, geralmente acima de cinco, são considerados igualmente anormais (1).

As características do fundo da lâmina de um espécime citológico não devem ser negligenciadas porque podem fornecer indícios quanto à natureza do material que está sendo examinado. Por exemplo, lâminas que contêm muitas células secretoras podem ter o material de fundo pesado por causa da acumulação do produto secretado. Um fundo finamente granulado nas lâminas de exsudatos inflamatórios pode ser observado em preparações coradas com azul de metileno novo e sugere um aumento no teor de proteínas. Um fundo grosseiro e granulado pode ser visto em lâminas preparadas com amostras contendo quantidades elevadas de mucopolissacarídeos como mucina, quando coradas por May Grunwald- Giemsa. A presença de bactérias, de cristais, de gotas de lipídeos, de materiais nucleares das células rompidas e de materiais estranhos como, por exemplo, pólen, talco ou cristais do amido, deve ser igualmente descrita no resultado. As amostras citológicas também podem conter quantidades variáveis de sangue periférico. A contaminação excessiva de sangue periférico em uma amostra de líquido ascítico mascara as células diagnósticas, tornando a interpretação citológica mais difícil (1).

8. Controle de qualidade das contagens: é de fundamental importância que se faça o controle de qualidade nas câmaras de contagem, evitando, assim, qualquer interferente que altere o resultado final da contagem. 0 controle de qualidade das contagens em câmara pode ser feito diluindo-se uma amostra de sangue total em EDTA e comparando-se os resultados obtidos manualmente com os obtidos em analisadores hematológicos automatizados. Para o controle da contagem de células nucleadas, deve-se escolher uma amostra com \pm 10.000 leucócitos/ $\mu$ l (valor obtido em contagem automatizada) e fazer a contagem manual em câmara de Neubauer, de preferência diluindo-se a amostra em líquido de Turk para hemolisar os eritrócitos. Quinzenalmente, deve-se verificar se houve contaminação dos diluentes (solução de fucsina, líquido de Turk e solução salina), examinando-os em câmara de contagem com aumento de 40x. Os diluentes contaminados com partículas ou fungos devem ser descartados e novas soluções devem ser preparadas. Semestralmente, é preciso realizar a manutenção preventiva da citocentrífuga para verificar a velocidade e o tempo de citocentrifugação (22). 
É fato que a contagem diferencial de neutrófilos manual e automatizada se correlaciona e pode ser intercambiável. Para garantir a qualidade da metodologia utilizada, pode-se fazer a adesão do laboratório a programas de controle de qualidade externos que realizem a análise do líquido ascítico (22).

9. Detecção de células malignas no líquido ascítico: doenças malignas, acompanhadas da cirrose, são as causas mais comuns de ascite. Independentemente do tempo de aparecimento, o achado de células neoplásicas nas efusões ascíticas está associado a uma significativa implicação terapêutica e prognóstica, pois é uma propagação celular alheia ao órgão de origem, portanto, uma progressão tumoral. As células malignas nos derrames são frequentemente encontradas entre os macrófagos e populações de células mesoteliais em efusões. Além disso, as células mesoteliais podem reagir a uma ampla variedade de estímulos e ferimentos, de modo que fiquem com morfologia semelhante às células malignas. Essas alterações podem ser ainda mais acentuadas após radioterapia ou quimioterapia associadas à cirurgias e tratamento dessas malignidades. Diante dessas implicações clínicas, diagnóstico preciso dessa condição é de fundamental importância (23).

9. Biossegurança: o líquido ascítico é uma amostra contaminante. Para tanto, é necessária a utilização dos equipamentos de proteção individual (EPI's) como avental ou jaleco longo de mangas compridas e punho retrátil, luvas descartáveis, óculos de proteção, pipetadores manuais ou automáticos e, quando for o caso, protetor facial. 0 ideal seria se todos os laboratórios possuíssem uma câmara de fluxo laminar vertical para maior proteção do operador (22).

\section{Referências}

1. Kjeldsberg C, Knight J. Body fluids: laboratory examination of cerebrospinal, seminal, serous \& sinovial fluids. 3rd ed. Chicago: American Society of Clinical Pathologists; 1992.

2. Kuiper JJ, Buuren HRV. Ascites in cirrhosis: a review of management and complications. Neth J Med. 2008; 66(4):177.

3. Margetts PJ, Brimble KS. Peritoneal dialysis, membranes and beyond. Curr Opin Nephrol Hypertens. 2006;15(6): 571-6.
4. Wal WJB, Jeekel J. Biology of the peritoneum in normal homeostasis and after surgical trauma. Colorectal Dis. 2007:9(Suppl 2):9-13.

5. Mutsaers SE. Mesothelial cells: their structure, function and role in serosal repair. Respirology. 2002;7(3):171-91.

6. Strasinger SK. Uroanálise e fluidos biológicos. 3a ed. São Paulo: Premier; 2000.

7. Burgess LJ. Biochemical analysis of pleural, peritoneal and pericardial effusions. Clin Chim Acta. 2004;343(1-2): 61-84.

8. Henry J. Diagnósticos clínicos e tratamento por método laboratorial. 20a ed. São Paulo: Manole; 2008.

9. Hutchison JG. Differential diagnosis of ascites. Semin Liver Dis. 1997;17(3):191-202.

10. Davies SJ, Phillips L, Griffiths AM, Russell LH, Naish PF, Russell GI. What really happens to people on long-term peritoneal dialysis? Kidney Int. 1998;54(6):2207-17.

11. Ji HL, Nie HG. Electrolyte and fluid transport in mesothelial cells. J Epithel Biol Pharmacol. 2008:1:1-7.

12. Kashani A, Landaverde C, Medici V, Rossaro L. Fluid retention in cirrhosis: pathophysiology and management. QJM. 2008;101(2):71-85.

13. Bibbo M, Longatto AF. Aspectos clínicos e laboratoriais dos derrames cavitários: conduta terapêutica e avaliações diagnósticas e prognósticas. Rio de Janeiro: Revinter; 2001.

14. Runyon BA, Montano AA, Akriviadis EA, Antillon MR, Irving MA, McHutchison JG. The serum-ascites albumin gradient is superior to the exudate-transudate concept in the differential diagnosis of ascites. Ann Intern Med. 1992:117(3):215-20.

15. Churchill DN, Thorpe KE, Nolph KD, Keshaviah PR, Oreopoulos DG, Pagé D. Increased peritoneal membrane transport is associated with decreased patient and technique survival for continuous peritoneal dialysis patients. J Am Soc Nephrol. 1998;9(7):1285-92.

16. Bennet JC, Plum F. Cecil-tratado de medicina interna. 20a ed. Rio de Janeiro: Guanabara Koogan; 1997.

17. Krige JEJ, Beckingham IJ. Portal hypertension-2. Ascites, encephalopathy, and other conditions. BMJ. 2001;322(7283):416-8. 
18. Leibovitch I, Mor Y, Colomb J, Ramon J. The diagnosis and management of postoperative chylous ascites. J Urol. 2002;167:449-57.

19. Koffel KK, Reed JS. The technique of abdominal paracentesis. J Crit Illn. 1986;1:45-50.

20. Wong CL, Holroyd-Leduc J, Thorpe KE, Straus SE. Does this patient have bacterial peritonitis or portal hipertension? How do I perform a paracentesis and analyze the results? JAMA. 2008;299(10):1166-78.
21. McGibbon A, Chen GI, Peltekian KM, van Zanten SV. An evidence-based manual for abdominal paracentesis. Dig Dis Sci. 2007;52(12):3307-15.

22. Comar SR. Procedimento operacional padrão: roteiro para análise de líquido ascítico. Curitiba: Hospital das Clínicas - Universidade Federal do Paraná; 2009.

23. Davidson B. Malignant effusions. Diag Cyto. 2004;31(4): 246-54. 
